\title{
Implikasi Peran Mandong Dayang Dalam Praktik Ritual Komunitas Dayak Lawangan
}

\author{
Ervantia Restulita L. Sigai \\ Institut Agama Hindu Negeri Tampung Penyang (IAHN-TP) Palangka Raya \\ restulita@gmail.com
}

\begin{abstract}
Riwayat Jurnal
Artikel diterima:4 Juli 2018

Artikel direvisi:10 Oktober 2018

Artikel disetujui: 12 November 2018

\section{Kata Kunci:}

Mandong dayang

Balian

Komunitas Dayak Lawangan

Lawangan Dayak community
Manword:
Balian dayan

\section{Abstrak}

Peran mandong dayang merupakan realitas sosial budaya yang tak terpisahkan dari struktur sosial budaya komunitas etnis Dayak Lawangan yang beragama Hindu (Hindu Kaharingan). Peran penting mandong dayang sebagai pendamping dan membantu balian (pemimpin ritual) dalam praktik ritual. Hubungan balian dengan mandong dayang merupakan hubungan relasi kuasa dan otoritas religius. Permasalahan yang diteliti adalah bagaimana proses menjadi mandong dayang, dan implementasi perannya dalam praktik ritual komunitas Dayak Lawangan di Kecamatan Dusun Tengah, Kabupaten Barito Timur, Kalimantan Tengah. Penelitian ini menggunakan metode kualitatif. Data dikumpulkan dengan teknik observasi, wawancara, dan studi dokumen. Analisis masalah menggunakan teori kekuasaan dan pengetahuan Michael Foucault dan teori praktik sosial Pierre Bourdieu. Hasil penelitian ini adalah sebagai berikut modal simbolik seorang mandong dayang diperoleh melalui proses berguru. Proses belajar calon mandong dayang meliputi dua tahap yaitu: (1) berhayak dan (2) nyawit nginte. Peran mandong dayang memiliki fungsi vertikal terkait aspek ritual puja bakti kepada Juus Tuha Alah Tala dan fungsi horisontal terkait fungsi sosial di dalam pranata sosial masyarakat. Mandong dayang mendapatkan otoritas praktik ritual. Otoritas tersebut dalam bentuk kuasa pengetahuan atas prestise sebagai pembantu balian. Otoritas tersebut menjadikan mandong dayang sebagai agen pembertahanan sebuah praktik ritual.

\section{Abstract}

The role of mandong dayang is a socio-cultural reality that is separated from the socio-cultural structure of the Hindu Dayak Lawangan community (Hindu Kaharingan). The vital part of mandong dayang is as a companion and helps balian (ritual leaders) in ritual practices. The relationship between balian and mandong dayang is a relationship between power and religious
\end{abstract}




\begin{tabular}{|l|l|}
\hline authority. The problems studied were how the process of \\
becoming a woman in court, and the implementation of her role \\
in the ritual practice of the Lawangan Dayak community in \\
Dusun Tengah, Barito Timur, Kalimantan Tengah. This study \\
uses a qualitative method. Data collected through techniques, \\
interviews, and document studies. Problem analysis uses Michael \\
Foucault's theory and knowledge and Pierre Bourdieu's theory of \\
social practice. The results of this study are as follows: symbol \\
capital that is useful for the learning process. The learning \\
process of prospective mandong dayang involves two stages, \\
namely: (1) berhayak dan (2) nyawit nginte. The role of \\
mandong dayang has a function related to the ritual aspects of \\
the worship of the worship to Juus Tuha Alah Tala and other \\
functions related to the social institutions of the community. \\
Mandong dayang is looking for religious practice rituals. The \\
authority is in the form of power over prestige as a balian helper. \\
The authority made mandong dayang in charge as an agent of \\
detention in a ritual of practice.
\end{tabular}

\section{Pendahuluan}

Bangsa Indonesia merupakan salah satu bangsa yang begitu besar dan memiliki begitu banyak ragam suku bangsa, ras, kesenian daerah, bahasa daerah, adat istiadat dan agama serta aliran kepercayaan. Agama adalah kesatuan sistem keyakinan dan praktek-praktek yang berhubungan dengan suatu yang sakral (Durkheim, 2003: 44). Sistem ritus dan upacara dalam religi berwujud aktivitas dan tindakan manusia dalam melaksanakan baktinya terhadap Tuhan, Dewa-dewa, roh nenek moyang, atau makhluk halus lain, dan sebagai bentuk usaha untuk berkomunikasi dengan Tuhan dan penghuni gaib lainnya. Ritus atau upacara religi biasanya terdiri dari suatu kombinasi yang merangkaikan satu, dua, atau beberapa tindakan, seperti berdoa, bersujud, bersaji, berkorban, makan bersama, menari dan menyanyi, berproses, berseni drama suci, berpuasa, intositasi, bertapa dan bersemedi (Koentjarangrat, 1985:44).

Asumsi filosofis ritus adalah manusia sebagai homo religious. Kottak (dalam Vianey, 2008: 28-29) menegaskan ritus sebagai representasi dan artikulasi dari religi yang memuat unsur verbal dan non-verbal. Unsur verbal dari dalam religi dalam ritus antara lain terungkap dalam doa, mitos, ajaran kearifan hidup berupa tuturan-tuturan ritual berbentuk ungkapanungkapan tradisional yang memuat pernyataan-pernyataan filosofis, teologis, dan moral yang berkaitan dengan manusia dan Tuhan. Dhavamony (1995: 175-176) membedakan ritus menjadi empat macam, yaitu: (1) tindakan magi, yakni tindakan yang dikaitkan dengan penggunaan bahan-bahan yang bekerja karena daya-daya magis; (2) tindakan religius; (3) ritual konstitutif, yang mengungkapkan atau mengubah hubungan sosial dengan merujuk 
pada pengertian-pengertian mistik sehingga dengan demikian upacara-upacara kehidupan menjadi khas; (4) ritual faktif, yakni meningkatkan produktivitas atau kekuataan, atau permurnian dan perlindungan, atau dengan kata lain meningkatkan suatu kesejahteraan materi dari suatu kelompok.

Menurut Hadi (1999: 29-30) ritual merupakan suatu bentuk perayaan yang berhubungan dengan beberapa kepercayaan atau agama yang ditandai dengan sifat khusus yang menimbulkan rasa hormat atau rasa luhur yang merupakan pengalaman yang suci. Sedangkan Endaswara (2003: 175) mengklasifikasi ritual menjadi dua yaitu: pertama, ritual krisis hidup, artinya ritual yang berhubungan dengan krisis hidup manusia. Manusia pada dasarnya akan mengalami krisis hidup ketika masuk dalam peralihan. Pada masa ini, manusia akan masuk dalam lingkup krisis karena terjadi perubahan tahap hidup, termasuk dalam lingkup ini antara lain kelahiran, pubertas dan kematian. Kedua, ritual ganguan, yakni ritual sebagai negosiasi dengan roh agar tidak menggangu hidup manusia. Praktik ritual Dayak Lawangan termasuk dalam semua klasifikasi tersebut.

Praktik ritual menjadi alat pengukur religiusitas komunitas Dayak Lawangan. Bagi komunitas Dayak Lawangan praktik ritual merupakan sebuah tindakan dan perbuatan manusia dalam rangka usaha menghubungkan dirinya dengan semua subjek keilahian yang dipandangnya amat mempengaruhi, dan menentukan kehidupan di masa depan. Orang Dayak Lewangan perpandangan religius oriented. Kepercayaan dan emosi keagamaan merupakan kekuataan yang menggerakkan seluruh sendi kehidupan mereka. Bagi komunitas Dayak Lawangan di Dusun Tengah, hubungan yang transendetal antara manusia dengan Tuhan diungkapkan dalam sejumlah acara ritual. Dalam tahapan siklus kehidupannya menjalankan ritual seperti balian palas bidan (ritual setelah kelahiran), balian ngasi ngado (ritual pernikahan), balian nyapu ipar (ritual setelah upacara kematian), dan balian ngansak (penyucian/ bersih desa). Pada setiap ritual komunitas Dayak Lawangan tidak bisa lepas dari peran balian dan mandong dayang. Balian adalah sebutan komunitas Dayak Lawangan kepada pemimpin ritual sedangkan mandong dayang merupakan sebutan bagi orang yang mendampingi balian dalam praktik ritual. Kata balian juga dilekatkan sebagai nama ritual.

Peran penting mandong dayang merupakan hubungan relasi yang saling sinergi dan terikat. Hubungan jaringan relasi antarposisi-posisi objektif dalam suatu tatanan sosial (Sigai, 2016: 103-104). Peran mandong dayang merupakan realitas sosial budaya yang tak terpisahkan dari struktur sosial budaya komunitas etnis Dayak Lawangan. Maka permasalahan yang akan dibicarakan adalah bagaimana proses menjadi mandong dayang, dan 
implementasi perannya dalam relasinya dengan pranata kehidupam komunitas Dayak Lawangan di Kecamatan Dusun Tengah, Kabupaten Barito Timur, Kalimantan Tengah.

\section{Metode}

Penelitian ini merupakan penelitian kebudayaan yang menggunakan metode kualitatif dan teknik analisis deskriptif-kualitatif. Menurut Faisal (2001: 15) metode kualitatif berkaitan erat dengan sifat unik dari realitas sosial dan dunia tingkah laku manusia itu sendiri. Sedangkan menurut Suparlan (1994: 25) yang menjadisasaran kajian atau penelitian kualitatif adalah kehidupan sosial atau masyarakat sebagai kesatuan yang menyeluruh (holistic). Metode kualitatif digunakan dalam pengumpulan dan analisis data yang menyadarkan pemahaman, dengan pendekatan makna-makna yang terkandung di dalamnya atau yang ada di balik kenyataan-kenyataan yang teramati (Patilima, 2005: 5). Dengan demikian, penekanannya bukan pada pengukuran, akan tetapi lebih pada penjelasan yang bersifat holistik sehingga pendekatan yang digunakan adalah pendekatan kajian budaya, yakni pendekatan etnografi, tekstual, dan resepsi (Barker, 2006 : 29).

Jenis dan sumber data penelitian ini, jenis data dalam penelitian ini adalah data kualitatif dan didukung data kuantitatif. Jenis data kualitatif berupa narasi, kata-kata, ungkapan, mantra, maupun uraian. Adapun jenis data kuantitatif dalam penelitian ini merupakan data pelengkap baik berupa angka-angka maupun statistik berhubungan dengan gambaran umum wilayah, seperti komposisi jumlah penduduk, agama dan kepercayaan, sosial ekonomi, dan tingkat pendidikan. Sedangkan sumber data, yaitu sumber data primer dan sumber data sekunder. Data primer adalah data yang diperoleh di lapangan, hasil wawancara dengan informan, sedangkan sumber data sekunder diperoleh melalui penelusuran berupa pustaka, penelitian terdahulu yang relevan dan data pendukung lainnya yang memperkaya penelitian ini.

Penentuan informan penelitian adalah informan-informan yang dipilih berdasarkan teknik purposive sampling, yaitu dipilih informan yang mempunyai pengetahuan, pengalaman dan pelaku mandong dayang. Teknik penentuan informan purposive sampling adalah menentukansubjek atau objek sesuai tujuan dengan menggunakan pertimbangan pribadi yang sesuai dengan topik penelitian, peneliti memilih subjek atau objek sebagai unit analisis (Satori, 2010: 47).

Instrumen penelitian yang akan digunakan dalam penelitian ini adalah pedoman wawancara. Daftar pertanyaan ini mengacu pada rumusan masalah . Penelitian ini menggunakan paradigma naturalistik yang salah satu karakteristiknya adalah human 
instrument (Danim, 2002: 135). Karakteristik manusia sebagai instrumen penelitian lebih mampu menyesuaikan diri dengan situasi tertentu, dapat membangun pengetahuan yang terkatakan maupun yang tak terkatakan (Lincoln dan Guba, 1985: 39).

Pengumpulan data yang dilakukan dalam penelitian ini adalah menggunakan teknik penelitian lapangan (field research), yakni peneliti melakukan pengumpulan data secara langsung di lokasi penelitian dengan menggunakan teknik observasi, wawancara mendalam (indepth interview) dan Studi dokumen. observasi merupakan kegiatan pengumpulan data. Observasi dilakukan secara sistematis maupun observasi partisipan. Observasi partisipan adalah sutau proses pengamatan yang dilakukan peneliti dengan ikut terlibat dalam kehidupan komunitas Dayak Lawangan menjadi "orang dalam" yang merasakan dan mengalami situasi secara pribadi. Di satu pihak peneliti juga sebagai "orang luar" yang dapat mengamati situasi dengan sikap yang lebih objektif. Manfaat observasi partisipan akan memperat hubungan peneliti dengan informan, sehingga data yang diperoleh semakin leluasa. Lebih dari itu, keterbukaan informan juga akan semakin lebar. Peneliti juga lebih memahami dari berbagai aspek atas budaya yang diteliti (Endraswara, 2006: 142).

Wawancara mendalam (indepth interview) dilakukan dengan cara tatap muka dan tanya jawab secara langsung dengan informan untuk mendapatkan informasi secara bebas dan mendalam mengenai proses menjadi mandong dayang, fungsi, dan implekasi perannya. Penelitian ini menggunakan teknik pertanyaan terbuka (open-ended interview). Teknik pertanyaan terbuka membuka kebebasan kepada informan untuk menjawab secara luas dengan bahasa, gayanya sendiri, lebih fleksibel terhadap situasi dan kondisi informan.Jawaban-jawaban tersebut dicatat, direkam oleh peneliti. Seluruh informasi diperoleh dari informan akan dijadikan bahan dasar, kemudian diklasifikasikan sesuai dengan kategori atau pengelompokan dalam analisis penelitian ini. Sedangkan studi dokumen dalam penelitian kualitatif merupakan pelengkap dari penggunaan teknik observasi dan wawancara. Dokumen merupakan sumber informasi non human resources.

Analisis data dilakukan secara deskriptif kualitatif dan interpretatif. Data yang sejak observasi ditelaah dari berbagai sumber, yaitu wawancara dan pengamatan yang terdiri dari catatan lapangan dan komentar peneliti, gambar, foto, artikel dan sebagainya. Teknik analisis data terdiri atas tiga proses yang saling terkait (Huberman dan Miles, 2009:592), yaitu: (1) reduksi data (data reduction), (2) penyajian data (data display), dan (3) pengambilan simpulan atau verifikasi. Laporan atau hasil kajian analisis disajikan secara informal dan formal. Teknik penyajian hasil analisis data informal (deskriptif-naratif), yakni menyajikan 
analisis data berupa uraian kata-kata dengan memaparkan keadaan subjek yang diselidiki sebagaimana adanya, berdasarkan fakta-fakta yang aktual pada saat penelitian dilakukan (Nawawi dan Hadari, 1992:67).

\section{Hasil Penelitian}

\section{Komunitas Dayak Lawangan}

Komunitas menurut Suparlan (2004: 117) adalah satuan kehidupan yang lebih kecil dari masyarakat, hidup dalam sebuah wilayah tertentu, dengan batas-batas wilayah yang jelas. Anggotanya saling terkait satu sama lain melalui jaringan sosial dan jaringan kekerabatan, karena garis keturunan dari satu nenek moyang yang sama atau karena melalui hubungan perkawinan. Sebuah komunitas mempunyai aturan, pengetahuan, nilai, dan norma yang dipakai sebagai acuan pedoman untuk bertindak dan memahami lingkungan hidupnya. Komunitas yang dimaksud dalam penelitian ini adalah orang Dayak Lawangan dengan budaya, tradisi, norma, nilai dan mitologi yang mengiringinya sebagai suku bangsa.

Menurut Riwut (2003:59) Dayak mempunyai sekitar 450 subsuku. Masyarakat Dayak secara umum saat ini dibedakan menjadi enam kelompok besar. Enam kelompok besar tersebut yaitu: Kenyah-Kayan-Bahau, Ot Danum, Iban, Murut, Klemantan dan Punan. Sukusuku tersebut terbagi lagi menjadi beberapa sub suku: Dayak Ngaju, Dayak Bakumpai, Dayak Ma'anyan, Dayak Lawangan, Dayak Siang, Dayak Murung, Dayak Dusun, Dayak Bawo, Dayak Sampit, OT Danum, Dayak Kotawaringin dan Dayak Taboyan (Riwut, 2003: 61). Durasid (1990: 47) menyatakan sebagai berikut.

Kelompok Barito itu dibagi atas tiga subkelompok, yaitu Barito Barat, yang terdiri atas bahasa Kahayan dan Dohoi, Barito Timur yang terdiri atas bahasa Maanyan dan subkelompok Lawangan-Dusun Deyah (yang terpisah menjadi bahasa Lawangan dan Duson Deyah), dan Barito - Mahakam, di sini diwakili bahasa Tunjung... penutur bahasa Lawangan bermukim di kabupaten administratif Barito Timur dan sekitarnya

Sub suku Dayak yang diteliti adalah komunitas etnis Dayak Lawangan yang berdomisili di, Kecamatan Dusun Tengah, Kabupaten Barito Timur, Kalimantan Tengah yang memiliki keyakinan Kaharingan atau dikenal luas di Kalimantan Tengah sebagai Hindu Kaharingan. Sistem kekerabatan etnis Dayak Lawangan berkembang berdasarkan hubungan darah berdasarkan prinsip keturunan ambilineal. Sistem kekerabatan berdasarkan prinsip keturunan ambilineal, yang menghitungkan hubungan kekerabatan untuk sebagian orang melalui orang laki-laki dan untuk sebagian melalui orang-orang wanita (Danandjaja, 2010: 128). Pada masa dahulu kelompok kekerabatan yang terpenting dalam masyarakat adalah 
keluarga-ambilineal kecil. Pada masa sekarang kelompok kekerabatan yang terpenting adalah keluarga luas utralokal lihat gambar 1 berikut ini.

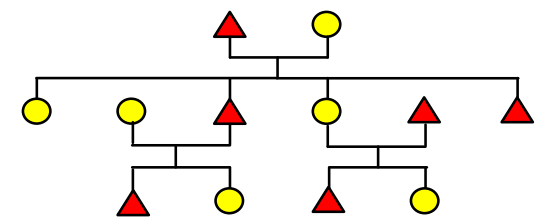

Gambar 4.9 Keluarga Luas Utrolokal

Sumber: Koentjaraningrat (1992)

\begin{tabular}{lll} 
Keterangan & $:$ & \\
$\square$ & $:$ & hubungan saudara kandung \\
$\triangle$ & $:$ & hubungan perkawinan \\
$\bigcirc$ & $:$ & laki-laki \\
\hline & $:$ gerempuan \\
\hline & garis keturunan
\end{tabular}

Gambar 1 bentuk keluarga luas-utralokal yang terdiri dari suatu keluarga inti senior dengan keluarga-keluarga batih anak-anak laki-laki maupun anak-anak perempuan. Utrolokal terjadi berdasarkan adat utrololokal, yaitu timbul karena sebagian dari anak-anak maupun perempuan sesudah kawin, membawa masing-masing keluarganya untuk tinggal dalam rumah orang tua dengan demikian menjadi suatu kesatuan sebagai keluarga-luas (Koentjarangrat, 1992: 117-118; Danandjaja, 2010: 128-129). Masing-masing keluarga tinggal dalam suatu ikatan keluarga batih yang terdiri atas orangtua, anak-anaknya dan kerabat orangtuanya. Seluruh keluarga batih yang masih berhubungan darah diikat dengan kekerabatan dalam satu keluarga luas (extended family). Satu keluarga luas terdiri atas dua tiga generasi keluarga (Sigai, 2016: 83).

\section{Proses Menjadi Mandong Dayang}

Pada zaman dulu profesi mandong dayang dipegang oleh istri balian, namun kondisi zaman sudah berubah. Era modernitas perubahan zaman begitu pesat yang berakibat pada perubahan tradisi (Sigai, 2016: 216). Seiring dengan perubahaan zaman profesi mandong dayang dapat digeluti semua orang. Perubahan tersebut menandakan pengetahuan terbentuk di dalam praktik kekuasaan dan membangun perkembangan, perbaikan dan profilerasi teknik baru kekuasaan (Barker, 2004: 83). Praktik ritual merupakan modal budaya komunitas Dayak Lawangan. Modal budaya dimensi yang lebih luas dari habitus, sekaligus menunjukkan lingkungan sosial pemiliknya dan modal budaya yang dapat berubah-ubah. 
Modul budaya terbentuk selama bertahun-tahun hingga terinternalisasikan dalam diri seseorang (Soeriadiredja, 2012: 10). Modal simbolik seorang mandong dayang diperoleh melalui proses dan tahapan yang panjang. Proses utama yang harus dilewati seorang mandong dayang adalah proses belajar. Proses menuntut ilmu secara lisan dengan para balian bawo tuha (senior) dan mandong dayang pendahulu.

Proses belajar calon mandong dayang meliputi dua tahap yaitu: tahap pertama berhayak mulai mempelajari sarana prasarana ritual dan susunan ritual. Selama proses berhayak calon mandong dayang akan belajar mengikuti kemanapun balian dan mandong dayang senior melaksankan ritual. Tahap kedua nyawit nginte merupakan proses belajar lanjutan untuk menyempurnakan pengetahuan mantra. Pada proses ngawit nginte seorang calon mandong dayang mempersembahkan pengandal sebagai syarat berguru. Pengandal berisikan beras, beras ketan, isi bowit (mata pancing), besi (pisau), benang putih, kain, tetalian (uang logam) dan ringgit (mata uanga Belanda) yang dimasukkan ke dalam sasangan (wadah mangkok yang terbuat dari kuningan) atau menggunakan mangkok putih sebagai wadah. Pengandal merupakan simbol personifikasi hakekat manusia, kelapa simbol kepala, gula simbol darah, benang simbol urat, kain simbol kulit, besi simbol tulang, dan uang merupakan lapisan roh. Ketika seorang murid mempersembahkan pengandal kepada guru (balian), guru menerima persembahan tersebut. Maka, murid tersebut telah diterima dan mulai belajar untuk memeroleh pengetahuan dari gurunya (Sigai, 2016: 100). Persembahan pengandal bermakna sebagai tanda kesungguhan, keiklasan, dan terima kasih seorang murid. Calon mandong dayang yang belum melewati tahap ngawit nginten tidak diperkenankan untuk mandiri mendampingi balian. Regulasi dijalankan mandong dayang menadakan kuasa tidak selalu bekerja melalui penindasan dan represi, akan tetapi terutama melalui normalisasi dan regulasi. Kuasa tidak bersifat destruktif melainkan produktif. Kuasa tidak menghancurkan tetapi menghasilkan sesuatu. Kuasa itu produktif, kuasa memungkinkan segala sesuatu (Bertens, 2014: 311-314).

Menuntut ilmu sebagai calon mandong dayang yang terpenting memiliki niat dan kesungguhan untuk belajar, akan tetapi terdapat perbedaan mandong dayang yang memiliki garis keturuan mandong dayang akan lebih berbakat dan cepat menguasai pelajaran dibandingkan yang tidak mempunyai garis keturunan. Jadi mandong dayang dapat diklasifikasi berdasarkan dua model, pertama, model belajar yaitu memperoleh keahlian melalui belajar, kedua model genealogi yaitu mendapatkan keahlian berdasarkan garis 
keturunan mandong dayang. Lihat gambar 2 garis pewarisan mandong dayang Ne Seria berikut ini.

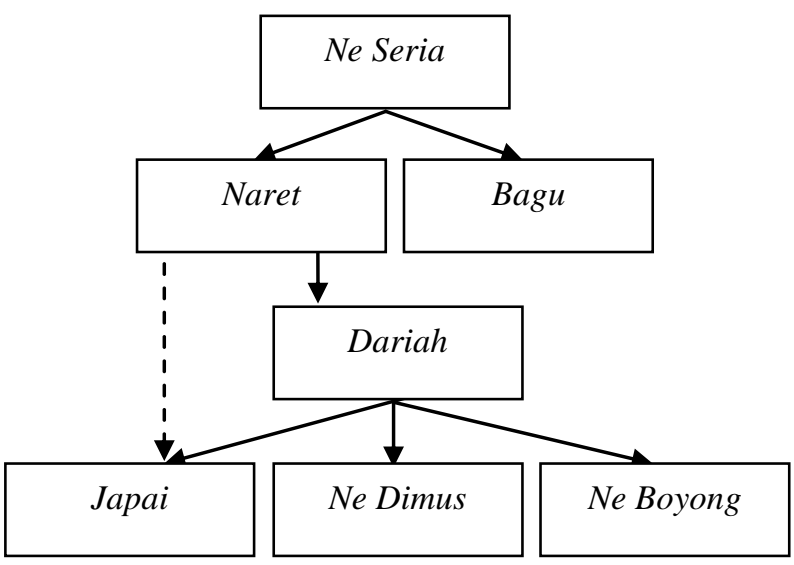

Gambar 2

Garis Pewarisan Mandong Dayang Ne Seria Pendamping Balian Sumber: Sigai (2016: 105)

Keterangan:

$\longrightarrow$ Menunjukan garis belajar

-.- Menunjukan garis keturunan

Pada gambar $2 \mathrm{Ne}$ Seria mewariskan ilmunya kepada Naret dan Bagu, kemudian Naret mewariskan ilmunya pada Dariah. Dariah melanjutkan mewariskan pada Japai, $\mathrm{Ne}$ Dimus dan Ne Boyong. Selain berguru pada Dariah, Japai juga berguru dengan Naret yang memiliki hubungan secara genealogis. Selain berguru dengan mandong dayang senior, dapat pula berguru dengan balian tuha seperti Dariah yang berguru dengan balian Sakal. Kemampuan mandong dayang dalam menyerap ilmu bersifat individual, oleh sebab itu tidak semua mandong dayang memiliki kemampuan yang sama walaupun berguru pada guru yang sama. Kemampuan mandong dayang dapat dikategoriakan dua tipe yaitu, pertama, mandong dayang yang memiliki kemampuan pengetahuan mumpuni mampu mengimbangi tuturan mantra balian ketika ritual berlangsung dan kedua, mandong dayang hanya sebagai pendamping tidak menguasai tuturan mantra.

\section{Implikasi Peran Mandong Dayang dalam Komunitas Dayak Lawangan}

Ritual merupakan agama dalam tindakan (Dhavamony, 1995: 167). Begitu pula memahami mandong dayang merupakan bagian penting dari pranata komunitas Dayak Lawangan. Ritual sebagai salah satu komponen pelembagaan agama atau religi adalah aktivitas manusia berupa pemujaan, permohonan atau pengungkapan rasa syukur dalam hubungannya dengan pengalaman yang suci dan sakral (Kontjaraningrat, 2009: 295). 
Mandong dayang memiliki peranan yang penting dalam praktik ritual komunitas Hindu Kaharingan Dayak Lawangan di Dusun Tengah. Profesi mandong dayang dipegang oleh seorang perempuan yang sudah menikah. Mandong dayang merupakan asisten dan tangan kanan balian. Tugas mandong dayang yaitu, (1) mempersiapkan sarana dan prasarana ritual, (2) menguasai prosesi dan tahapan ritual, (3) mitra diskursus bertutur balian bawo dalam praktik ritual, dan (4) perantara komunikasi antara balian bawo dan penanggab hajat/ tuan rumah acara. Mandong dayang sebagai mitra dikursus menghasilkan pengetahuan dan praktik sebagaimana pandangan Foucault (2002: 9) yang menegaskan bahwa diskursus adalah cara menghasilkan pengetahuan, berserta praktik sosial yang menyertainya, bentuk subjektivitas yang terbentuk darinya, relasi kekuasaan yang ada di balik pengetahuan dan praktik sosial tersebut, serta saling keterkaitan di antara semua aspek. Mandong dayang tidak memiliki wilayah kerja yang tertulis secara pasti, mereka cendrung mengikuti balian. Namun, pada umumnya komunitas Dayak Lawangan mengundang mandong dayang berdasarkan kesamaan wilayah tempat ringgal, wilayah tersebut dapat dipetakan lihat tabel 1 berikut ini .

\section{Tabel 1}

\section{Mandong Dayang Pendamping Balian/Balian Bawo \pm Tahun 1900 s.d. Sekarang Di Dusun Tengah}

\begin{tabular}{llll}
\hline No & \multicolumn{1}{c}{ Mandong Dayang } & \multicolumn{1}{c}{ Cakupan Wilayah Kerja } & Keterangan \\
\hline 1 & Mamirim & Seluruh Kabupaten Barito Timur & Meninggal \\
\hline 2 & Ne Ngasam & Seluruh Kabupaten Barito Timur & Meninggal \\
\hline 3 & Ne Rasul & Seluruh Kabupaten Barito Timur & Meninggal \\
\hline 4 & Risam & Seluruh Kabupaten Barito Timur & Meninggal \\
\hline 5 & Ne Bue & Seluruh Kabupaten Barito Timur & Meninggal \\
\hline 6 & Ne Nilam & Seluruh Kabupaten Barito Timur & Meninggal \\
\hline 7 & Ne Wikal/ Ne Nili & Seluruh Kabupaten Barito Timur & Meninggal \\
\hline 8 & Ne Jagai & Seluruh Kabupaten Barito Timur & Meninggal \\
\hline 9 & Ne Banjar (Naret) & Seluruh Kabupaten Barito Timur & Meninggal \\
\hline 10 & Tak Ne Isa & Seluruh Kabupaten Barito Timur & Meninggal \\
\hline 11 & Ne Biran (Dariah) & Seluruh Kabupaten Barito Timur & Sakit \\
\hline 12 & Ne Boyong & Seluruh Kabupaten Barito Timur & Sakit \\
\hline 13 & Ne Sumi/ Ne Japut (Japai) & $\begin{array}{l}\text { Kelurahan Ampah \& Desa Bantai Karau } \\
\text { (Kecamatan Dusun Tengah) }\end{array}$ & Sehat \\
\hline 14 & Ne Dimus & $\begin{array}{l}\text { Desa Netampin } \\
\text { (Kecamatan Dusun Tengah) }\end{array}$ & Sehat \\
\hline 15 & Ne Yama (Dabuk) & $\begin{array}{l}\text { Desa Hayaping \& Desa Rodok } \\
\text { (Kecamatan Dusun Tengah) }\end{array}$ & Sehat \\
\hline
\end{tabular}

Sumber: Sigai (2016: 106)

Tabel 1 terlihat tidak semua wilayah dapat dijangkau oleh para mandong dayang akibat luasnya wilayah Dusun Tengah dan kabupaten Barito Timur. Kebanyakan para 
mandong dayang memenuhi permintaan masyarakat yang masih dalam teritorial wilayah tempat tinggal mereka, kecuali mandong dayang senior lebih sering digunakan jasanya di luar wilayah Dusun Tengah. Maramin, mandong dayang tertua bergelar Ara Baka Tukar Tondoi. Segenerasi dengan Mamirim, yaitu Ne Ngasam, Ne Rasul, Risam, Ne Biran, Ne Japut (Japai), $N e$ Bue, $N e$ Nyilam, $N e$ Wikal atau $N e$ Nili.

Mandong dayang memiliki otoritas rohani dan sangat dihormati dan dihargai karena kemampuan sebagai pendamping balian. Posisi seorang balian bawo bawo menarik berbagai kepentingan sebagai alat legitimasi religiusitas (Sigai, 2016: 103). Begitupula dengan mandong dayang, otoritas rohani yang dimilikinya merupakan bagian strategi investasi simbolik. Modal simbolik merupakan peluang bagi mandong dayang membentuk otoritas sosial. Profesi tersebut menciptakan kekuasaan simbolik merupakan kekuasaan untuk mengkontruksi realitas. Sejalan kekuasaan simbolik menurut Bourdieu (dalam Fashri, 2014: 142-143), yaitu:

Pertama, seperti halnya wacana formatif kekuasaan simbolik didasarkan pada kepemilikan modal simbolik (symbolic capital); semakin besar seseorang atau satu kelompok memiliki modal simbolik semakin besar peluangnya untuk menang. Artinya, modal simbolik merupakan kredit terbentuknya otoritas sosial dari pertarungan sebelumnya. Kedua, bergantung pada efektivitas simbolik, tempat strategi investasi simbolik bekerja. Efektivitas bekerja ini atas dasar pandangan yang ditawarkan atau sejauh mana strategi investasi simbolik dijalankan.

Strategi investasi simbolik yang terjadi berwujud hubungan relasi antara balian dan mandong dayang. Hubungan relasi antarposisi dalam suatu tatanan praktik ritual. Hubungan tersebut merupakan bagian integral dari pranata komunitas Dayak Lawangan. Keduannya menjalin sinergitas praktik ritual. Jalinan sinergitas tersebut memberikan relasi kuasa pengetahuan. Menurut Bourdieu (dalam Agusta, 2014: 31) kebenaran suatu pengetahuan menginduksi, dalam hal ini subjek membentuk kondisi-kondisi objektif agar suatu pengetahuan dapat muncul keperemukaan arena sosial. Kekuasaan balian dan mandong dayang menghasilkan subjek atau agensi. Hubungan balian dan mandong dayang sangat tergantung proses adaptasi, integrasi yang mengatur antarhubungan relasi, penyesuaian kebutuhan dan pemeliharaan pola-pola kultural yang menopang life cycle rites komunitas Dayak Lawangan (Sigai, 2016: 90).

Posisi mandong dayang dalam hierarki kekuasaan balian secara vertikal dapat dilihat pada gambar 3 berikut ini. 


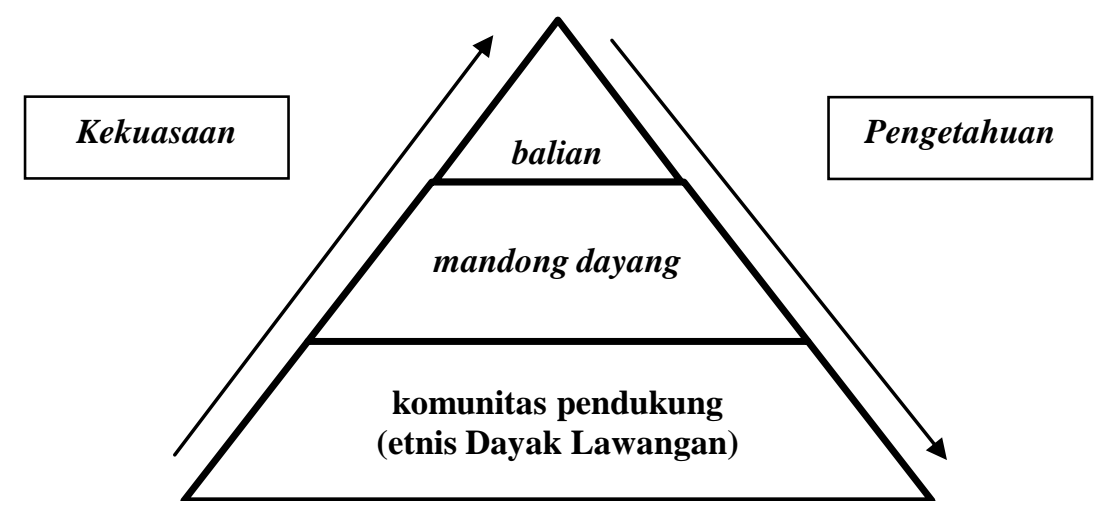

Gambar 3 Hierarki Kekuasaan Balian

Sumber: Diadaptasi dari Waters (dalam Sigai, 2016: 128)

Pada gambar di atas terlihat bahwa dua anak panah menunjukkan saling berhubungan dan saling umpat balik fungsinya. Subsistem yang berada lebih tinggi, yaitu balian berfungsi memberi kontrol informasi pengetahuan kepada yang di bawahnya. Sementara subsitem yang berada lebih rendah atau di bawah berfungsi memberikan umpan balik kekuataan (wewenang) kepada subsistem yang lebih tinggi (Sigai, 2016: 128). Posisi mandong dayang sangat strategis berada dalam oposisi biner antara balian dan komunitas pendukungnya. Posisi tersebut memberikan hubungan kekuasaan (power relationship) bagi mandong dayang sebagai peyambung tuturan balian kepada komunitas Dayak Lawangan. Hubungan kekuasaan tersebut menurut Foucault (dalam Sarup, 2003: 124-128) menyatakan bahwa:

Kekuasaan menciptakan realitas dan kekuasaan menciptakan domain objek dan ritual kebenaran. Pelaksanaan kekuasaan itu sendiri menciptakan dan melahirkan objek pengetahuan yang baru. Sebaliknya, pengetahuan menciptakan pengaruh-pengaruh kekuasaan. Tanpa pengetahuan kekuasaan tidak mungkin dijalankan, pengetahuan tidak mungkin tidak melahirkan kekuasaan.

Kekuasaan terartikulasi kedalam pengetahuan dan sebaliknya pengetahuan terartikulasi ke dalam kekuasaan. Dengan kata lain, kekuasaan tidak hanya punya relasi dengan pengetahuan, melainkan kekuasaan terdiri atas pengetahuan, sebagaimana halnya pengetahuan juga terdiri atas kekuasaan (Suryawan, 2010: 121). Pengetahuan selalu berkaitan dengan kekuasaan. Keduanya saling menguatkan satu sama lain, misalnya berbekal pengetahuan psikologi seseorang mempunyai kekuasaan untuk menghakimi kondisi mental orang lain (Foucault, 2002: 23). Menurut Alkausar (2011: 45) ritual mempunyai fungsi pertama, ritual akan mampu mengintegrasikan dan menyatukan kelompok masyarakat, berarti ritual menjadi alat pemersatu atau interaksi. Kedua, ritual juga menjadi sarana pendukung untuk mengungkapkan emosi keagamaan; dan ketiga, ritual akan mampu 
melepaskan tekanan-tekanan sosial. Ritzer (2000: 25) menyatakan bahwa setiap pranata sosial dan aktivitas manusia berfungsi sebagai penopang bagi keberadaan pranata dan aktivitas sosial yang lain dari manusia itu dan komunitasnya.

Peran mandong dayang memiliki fungsi vertikal dan horisontal, fungsi vertikal terkait dengan aspek ritual dan fungsi horisontal terkait fungsi sosial di dalam pranata sosial masyarakat. Pada tataran vertikal mandong dayang sebagai pembantu balian menjembatani individu terhubung dengan kekuatan-kekuatan transenden melalui ritual sebagai bentuk persembah bakti kepada Juus Tuha Alah Tala. Mandong dayang memiliki otoritas praktik ritual. Otoritas tersebut dalam bentuk kuasa atas prestise sebagai pembantu balian. Otoritas tersebut menjadikan mandong dayang sebagai agen pembertahanan sebuah tradisi. Hubungan mandong dayang dengan komunitas pendukungnya merupakan hubungan fungsional, ketergantungan dan timbal balik. Ketergantungan tersebut muncul dari kebutuhan religius orang Dayak Lawangan akan praktik ritual. Terbentuk habitus komunitas Dayak Lawangan menciptakan kergantungan. Habitus adalah struktur kognitif yang memperantarai individu dan realitas sosial (Harker, dkk, 2009: 13).

Konsensus selalu terjadi antara balian, mandong dayang, dan komunitas pendukungnya. Tanpa komunitas pendukungnya maka hampir mustahil praktik ritual dapat terselenggara. Peran mandong dayang merupakan bagian integral balian yang tak terpisahkan. Namun ketiadaan penanggap balian untuk kepentingan ritual hampir dapat dipastikan mandong dayang tidak akan berfungsi. Ketidaktertarikan generasi muda berprofesi sebagai mandong dayang menandakan tidak adanya komunikasi yang efektif yang terjadi antara generasi muda dan generasi tua sehingga menyebabkan hilangannya kontrol terhadap sistem sosial budaya. Kontak dengan kelompok-kelompok lain menyebabkan masuknya gagasan-gagasan dan cara baru untuk mengerjakan sesuatu yang akhirnya menimbulkan perubahan nilai perilaku tradisonal (Haviland, 1998: 250-252). Sedyawati (2002: 138-139) mengungkapkan sebagai berikut.

Adanya perubahan disebabkan oleh faktor internal dan eksternal. Faktor internal adalah perubahan kebudayaan yang datang dari masyarakat pendukung kebudayaan itu sendiri yang disebabkan oleh berbagai macam dorongan, antara lain tantangan dari perubahan yang sifatnya alami dan demikian bermaknanya perubahan tersebut sehingga manusia didorong ke arah suatu keharusan untuk menyesuaikan diri, artinya mengadakan tindakan-tindakan perubahan.

Menurut Sigai (2016: 225) intensitas frekuensi ritual memberi pengaruh terhadap transmisi budaya. Proses transmisi tradisi menjadi penting karena praktik ritual merupakan pranata sosial budaya yang menyeluruh. Bagi individu yang jarang melaksanakan ritual 
aksesnya semakin jauh dengan nenek moyangnya. Upacara berfungsi untuk mengembalikan dan mengingatkan kembali keanggotaan seseorang dalam kelompok kerabatnya (Rudito, 2013: 26). Sejalan dengan pendapat Bambang Rudito (2013: 194) menyatakan bahwa:

Upacara akan menguatkan jiwa manusia. Upacara menguatkan hubungan antarmanusia dan hubungan antarmanusia dan lingkungan. Manusia berpergian atau tinggal di luar daerah akan dipanggil untuk berkumpul di rumah komunal, dan berintraksi kembali dengan roh nenek moyang. Hal ini akan menguatkan ikatan kekerabatan antarkeluarga luas. Mereka bisa membentuk aliansi kekerabatan yang akan memperkuat kedudukannya dalam masyarakat yang lebih luas.

Selama praktik ritual tetap berlangsung eksistensi kuasa mandong dayang akan terjaga. Kuasa yang membentuk staregi-strategi untuk bertahan dengan modal simbolik. Kuasa yang dipraktikkan melaui ritual. Menurut Foucault (2002: 23), pengetahuan selalu berkaitan dengan kekuasaan. Pengetahuan mandong dayang memberikan legitimasi terhadap komunitas Dayak Lawangan.

\section{Simpulan}

Mandong dayang memiliki peranan yang penting dalam praktik ritual komunitas Hindu Kaharingan Dayak Lawangan di Dusun Tengah sebagai pendamping Balian. Profesi sebagai mandong dayang merupakan sebuah panggilan jiwa, profesi yang mulia, dan membutuhkan komitmen seumur hidup untuk melayani umat dan masyarakat. Hubungan antara balian dan mandong dayang mencitptakann relasi antarposisi dalam tatanan praktik ritual. Profesi mandong dayang sebagai pembantu Balian memberikannya prestise dalam tatanan komunitas Dayak Lawangan. Prestise yang diperoleh mandong dayang merupakan modal simbolik. Mandong dayang memiliki otoritas dalam praktik ritual. Otoritas tersebut dalam bentuk kuasa pengetahuan sebagai pembantu balian. Otoritas tersebut menjadikan mandong dayang sebagai agen pembertahanan sebuah tradisi. Selama praktik ritual tetap berlangsung eksistensi kuasa mandong dayang akan terjaga. Kuasa yang membentuk staregistrategi untuk bertahan dengan modal simbolik.

\section{Daftar Pustaka}

Agusta, Ivanovich .(2014). Diskursus, Kekuasaan, dan Praktik Kemiskinan di Pedesaan. Jakarta: Yayasan Pustaka Obor Indonesia.

Alkausar, Muhamad .(2011). "Keterancaman Ritual Mappandesasi dalam Masyarakat Nelayan Etnik Mandar Kelurahan Bungkutoko Sulawesi Tenggara”. Tesis. Denpasar: Universitas Udayana.

Barker, Chris ,(2014). Kamus Kajian Budaya. Yogyakarta: Kanisius.

Bertens, K .(2014), Sejarah Filsafat Kontemporer Prancis Jilid II. Jakarta: PT. Gramedia Pustaka Utama. 
Danandjaja. $J$.(2010). “Kebudayaan Penduduk Kalimantan Tengah”. Dalam: Koentjaraningrat., (ed). Manusia dan Kebudayaan di Indonesia. Jakarta: Djambatan.

Danim, Sudarwan .(2002). Menjadi Penelitian Kualitatif: Rancangan Metodologi, Presentasi, dan Publikasi Hasil Penelitian untuk Mahasiswa dan Peneliti Pemula Bidang Ilmu-Ilmu Sosial, Pendidikan, dan Humaniora. Bandung: CV. Pusaka Setia.

Prenada Media Group

Dhavamony, M .(1995). Fenomena Agama. Yogyakarta: Kanisius.

Durasid, Durdje .(1990). "Rekonstruksi Protobahasa Barito". Disertasi. Jakarta: Fakultas Pascasarjana Universitas Indonesia.

Durkheim, Emile .(2011). Sejarah Agama (The Elementary Forms of The Religious Life). (Inyiak Ridwan Muzir dan M. Syukri, Pentj). Yogyakarta: IRCiSoD.

Endaswara, Suwardi .(2006). Metodologi Penelitian Kebudayaan. Yogyakarta: Pustaka Widyatama.

Endaswara, Suwardi .(2006). Metodologi Penelitian Kebudayaan. Yogyakarta: Pustaka Widyatama.

Faisal, Sarapiah .(2001). Varian-Varian Kontemporer Penelitian Sosial. Dalam: Burhan Bugin.,(ed). Metode Penelitian Kualitatif. Jakarta: PT. Raja Grasindo Persada.

Fashri, Fausi .(2014). Pierre Bourdieu: Menyingkap Kuasa Simbol. Yogyakarta: Jalasutra.

Foucault, Michael .(2002). Power/Knowledge: Wacana Kuasa/Pengetahuan. Yogyakarta: Bentang.

Gepu, Wayan .(2009). "Upacara Balian Palas Bidan Pada Masyarakat Hindu Kaharingan Suku Lawangan di Desa Putai Kabupaten Barito Timur Kalimantan Tengah (Kajian Bentuk, Fungsi, dan Makna)". Tesis. Denpasar: Institut Hindu Dharma Negeri.

Hadi, Y. Sumandiyo .(2006). Seni dalam Ritual Agama. Yogyakarta: Yayasan untuk Indonesia.

Harker, Richard, Cheelen, dan Chris Wilkes (ed). (2009). (Habitut X Modal) + Ranah = Praktik, Pengantar Paling Komperhensif Kepada Pemikiran Pierre Bourdieu. (Pipit Maizier, Pentj). Yogyakarta: Jalasutra.

Haviland, William .(1988). Antropologi Jilid I. (R.G Soekadijo, Pentj). Jakarta: Erlangga.

Hubermen, A. Michael., Mattew B. Miles .(2009). "Manajemen Data dan Metode Analisis". Dalam: Denzin, Norman K., \& Lincoln, Yvonna S., (ed). Handbook of Qualitative Research (Dariyatno, dkk, Pentj). Yogyakarta: Pustaka Pelajar. Hal: 591-612.

Koentjaraningrat .(1985). Ritus Peralihan Di Indonesia. Jakarta: PN. Balai Pustaka. .(1992). Beberapa Pokok Antropologi Sosial. Jakarta: Dian Rakyat.

Lincoln, Yvonna S., Egon G. Guba .(1985). Naturalistic Inquiry. California: SAGE Publication. Inc.

Nawawi, Hadari \& Martini, Hadari .(1995). Instrumen Penelitian Bidang Sosial. Yogyakarta: Gadjah Mada University Press.

Patilima, Hamid .(2005). Metode Penelitian Kualitatif. Bandung: CV. Alfabeta.

Ritzer, George .(2000). Sosiologi Ilmu Pengetahuan Berparadigma Ganda. Jakarta: Grafindo.

Riwut, Cilik .(2003). Maneser Panatau Tatu Hiang, Menyelami Kekayaan Leluhur. Nila Riwut., (ed). Yogyakarta: Pusaka Lima.

Rudito, Bambang .(2013). Bebetei Uma Kebangkitan Orang Mentawai: Sebuah Etnografi. Yogyakarta: Penerbit Gading dan Indonesia Center for Sustainable Developmen (ICSD).

Sarup, Madan .(2003). Posstrukturalism and Postmodernism, Sebuah Pengantar Kritis. Yogyakarta: Jendela. 
Satori, Djam'an., Komariah, Aan .(2010). Metodologi Penelitian Kualitatif. Bandung: Alfabeta.

Sedyawati, Edi .(2002). Kebudayaan dan Pembangunan dalam Masalah Budaya dan Pariwisata dalam Pembangunan. Denpasar: Program Studi Magister (S2) Kajian Budaya, Universitas Udayana.

Sigai, Ervantia Restulita L .(2016). "Eksistensi Balian Bawo Dayak Lawangan di Dusun Tengah, Barito Timur, Kalimantan Tengah". Disertasi. Denpasar: Program Pasacasarjana, Universitas Udayana.

Soeriadiredja, Purwadi .(2012). Reflektifitas: Representasi dan Politik dalam Karya Etnografi. Denpasar: Program Studi Antropologi, Fakultas Sastra dan Budaya, Universitas Udayana.

Suparlan, Parsudi .(2004). Hubungan Antar Suku Bangsa. Jakarta: YPKIK.

$$
\text { .(1994). Metode Penelitian Kualitatif. Jakarta: Program Kajian }
$$

Wilayah Amerika-Universitas Indonesia.

Suryawan, I Ngurah .(2010). Genealogi Kekerasaan dan Pergolakan Subaltern: Bara di Bali Utara. Jakarta: Prenada Media Group.

Vianey, Watu Yohanes .(2008). "Representase Citraan llahi dan Insani dalam Entitas Ritus Sa'o Ngaja di Kampung Guru Sina, Kabupaten Ngada, Flores”. Tesis. Denpasar: Program Pascasarjana Universitas Udayana 
